
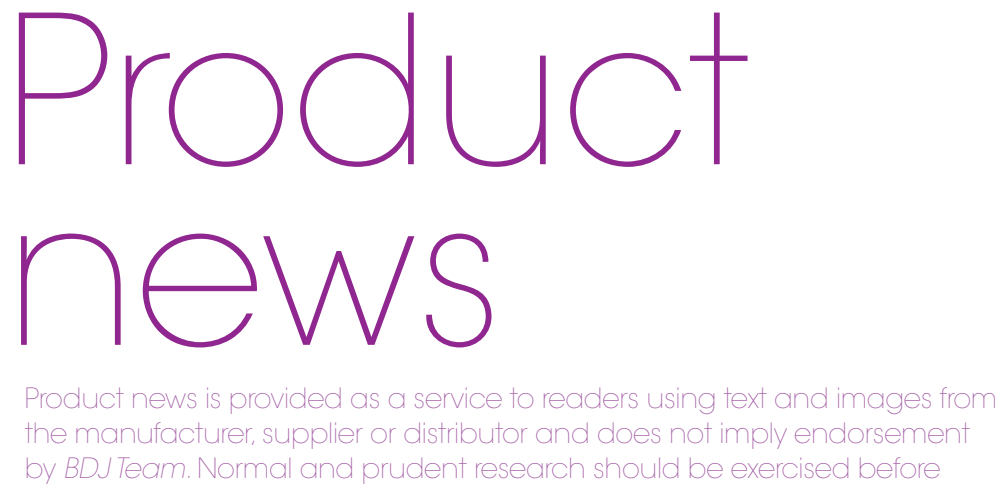

\title{
STATE OF THE ART CUSTOMER EXPERIENCE CENTRE AND HEAD OFFICE OPENS
}

Situated just outside Coventry and within the spectacular Ricoh Arena - home to the Wasps, Europe's most progressive rugby club - Planmeca welcomed their new distribution partners and esteemed guests to officially open a new customer experience centre and UK headquarters. event, but wished the local team and distribution partners well for the future.

Via their new and expanded distributor network, alongside a world class product portfolio and innovative mobile showroom, Planmeca are now well positioned across the UK and Ireland. Any dentist or DCP wanting to experience Planmeca's innovative digital workflow now has that opportunity through multiple channels and in multiple environments.

The new customer experience centre features a dedicated CAD/ CAM training zone alongside a full range of 3D imaging machines showcasing the latest in imaging technology. The showroom also includes Planmeca's range of digital dental units, all combined through the comprehensive and modular Romexis software. The showroom can be easily transformed into a small conference and event facility

The showroom was opened by Tuomas Lokki, Planmeca Group Senior Vice President and Karl O'Higgins Managing Director of Planmeca UK.

Tuomas said: 'This is a new era for Planmeca UK and our new home is one of the most important foundations from which success can be built upon. This new facility offers the perfect environment to discover our range of digital imaging solutions, world class CAD/CAM system and our range of highly innovative digital dental units.'

Karl echoed Tuomas's comments by saying that the stunning facility is testament to Heikki Kyöstil『’s vision for Planmeca UK to be an integral part of Planmeca's global success - Mr Kyöstil $\bigotimes$ is founder and president of the Planmeca Group, who unfortunately could not be present for the capable of hosting courses for up to 40 delegates.

The showroom is equipped with the latest technology to ensure seamless presentations with full HD LED projectors and multi speaker surround sound installed, ensuring a seamless experience for both presenters and delegates. There are a number of meeting rooms available, all of which are equally fitted out with the latest conference technology and catering is available from the Ricoh Arena in-house hospitality team. If you have need for a high quality Midlands lecture and events facility, give them a call.

To view the complete range of Planmeca digital solutions at their NEW customer experience centre, call 0500500686 or alternatively email marketing@planmeca. com.

\section{EXPLORING THE WORLD OF SCIENCE IN ORAL HEALTH}

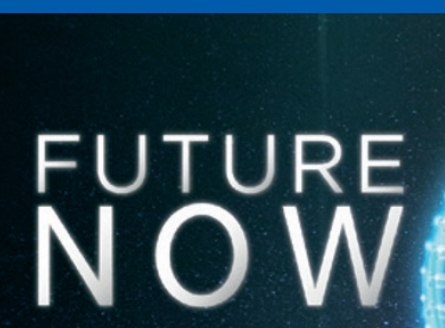

A World of Science in Oral Health
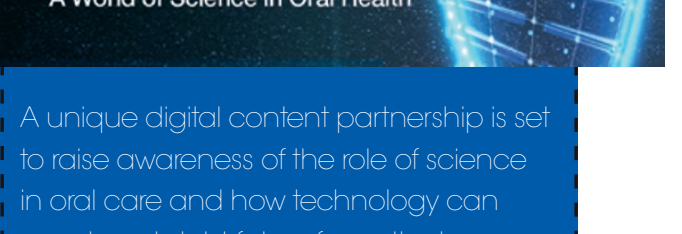

promise a bright future for patients

Sensodyne, manufactured by GS

Consumer Healthcare, has announced

a partnership with Discovery Network

to develop a global digital content

series. Future Now is a four-part series

of short documentaries exploring how

technology and science are impacting

on healthcare, particularly oral health. The

thought provoking content is available

to view now at http: / / www. discoveryuk

com/future-now.

Topics in the series include repairing

the human body and the role of Bioglass

technologies, how the technology

developed for space exploration is giving

insight into the oral environment and how

modern lifestyles are impacting on our

bodies. The series takes us back in time,

considers current challenges and looks at

how technology could help offer patients

a brighter future

'Sensodyne has been dedicated to

helping people care for their sensitive

teeth for over 50 years with its range

of science based products', says Dr

Teresa Layer, VP Oral Health Research \&

Development GSK

Videos will be available online for

patients and professionals to view until

December 2015

Thought provoking

content is available

to view now at http://

www.discoveryuk.com/ future-now 